\title{
Analysis of the correlation between deformation and temperature in a concrete dam
}

\author{
[Julio Manuel de Luis Ruiz, Raúl Pereda García, Felipe Piña García, Rubén Pérez Álvarez]
}

\begin{abstract}
Deformational control of structures has its greatest exponent in large dams monitoring, which, depending on their structural typology, can be subjected to movements generally based on both the pressure that they support and the temperature.

The designer usually calculates the theoretical displacements that the dam will suffer considering the hydrostatic thrust and the temperature, but it is also true that these displacements are theoretical and they do not often fit to the real movements, due to the uncertainties that arise during the construction of any dam and make the final structure have changes which can be more or less significant with respect to the originally projected one. However, it is worth mentioning that they are usually lower than those theoretically calculated.
\end{abstract}

The present research work focuses on a potential correlation and the subsequent determination of an empirical model that allows calculating the deformation by means of a polynomial fit, working on the basis of temperature observations held over 14 years. This empirical model is contrasted and validated with the observations taken during the following year, and although it is only valid for the dam where the test has been made ("La Cohilla" Dam), the methodology is suitable for any other structure.

Keywords - Auscultation, geometric control, pendulum, hydrostatic thrust, temperature.

\section{Introduction.}

Current legislation in Spain requires enterprises which own big dams to subject them to periodical geometric controls in order to guarantee a good structural functioning.

Julio Manuel de Luis Ruiz. Researcher ID: B-4956-2015

School of Mining and Energy Engineering / University of Cantabria Spain

Raúl Pereda García. Researcher ID: B-5240-2015

School of Civil Engineering / University of Cantabria Spain

Felipe Piña García. Researcher ID: B-5710-2015

School of Civil Engineering / University of Cantabria Spain

Rubén Pérez Álvarez. Researcher ID: B-8959-2015

School of Mining and Energy Engineering / University of Cantabria Spain
On this purpose, adequate instrumentation for geometrical state detection, and therefore, for the tensional state of the structure, is installed on them. Main instrument applied for the determination of structure state is the pendulum-plumb, which, with independence of being direct or inverse, continuously registers the movement developed by the point of the structure where the pendulum-plumb itself is placed. So as to measure the variables that affect that behavior, topographic equipment to determine the height of the water stored, and meteorological stations which allow defining temperature are used. In addition to this, other instrumentation can be applied to develop the geotechnical analysis of the environment, such as piezometers, inclinometers, load cells, etc.

When the designer develops the dam project, a hypothesis series is generally applied to calculate the theoretical range of movement that the dam will have in case it is needed to, as not every constructive typology require structure displacements against external stress. That range does not usually match the real one, due to the imponderables which arise through the structure construction and avoid it from exactly adjusting to the project. As a result, it is necessary to establish the real framework of the displacement obtained once the structure is under operation, which usually undergoes on the basis of observations taken with pendulum-plumb and the instrumentation to determine the variables that affect the stress state of the structure. This work aims to analyze the relation between structure planimetric radial displacements and the temperature, in order to establish a hypothetical correlation for predictive purposes.

\section{Instrumentation and Materials.}

All the data applied for this research work correspond to the observations held in a large dam called La Cohilla Dam, which is located in Cantabria, Spain. This dam configures a 10-cubic-hectometer reservoir which is the head dam of a hydroelectrical facility called Saltos del Nansa, that comprises three dams located through River Nansa (dowstream), shaping the facility itself.

Due to its constructive typology and changes in the conditions of variables that determine stress state, radial displacements up to $12 \mathrm{~mm}$ in the center of dam crown happen. In addition to this circumstance, the availability of both instrumentation (pendulum-plumb and meteorological station) and observations provide an ideal case for this research. The following figure shows this structure dimensions, which is characterized by an arch type construction of about 110 meters height and 240 meters width. 


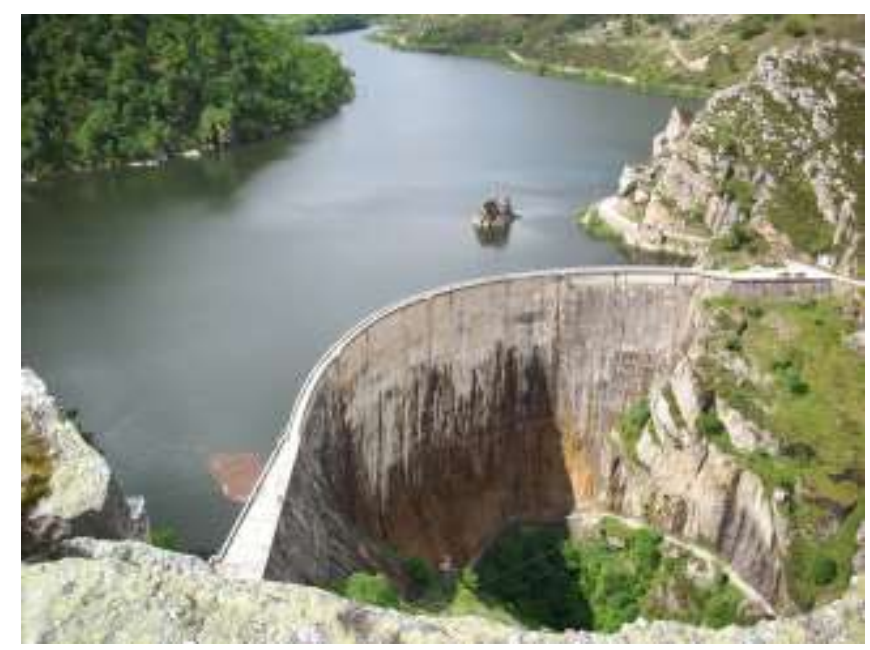

Figure 1. La Cohilla Dam (Cantabria/Spain).

The pendulum-plumb basically consists of a long thread with a mass located at its lower end. When Gravitatory Field acts on the mass, gravity force is produced, it tightens the thread and keeps it in force lines directions (vertical). In La Cohilla Dam case, the pendulum-plumb is direct and is placed on top of the central part of the dam, being the part which is out of the structure protected by a pipe.

As the pendulum-plumb is placed at its uppest part, any movement that could arise there is transferred to the bottom, where the reading micrometer is located.

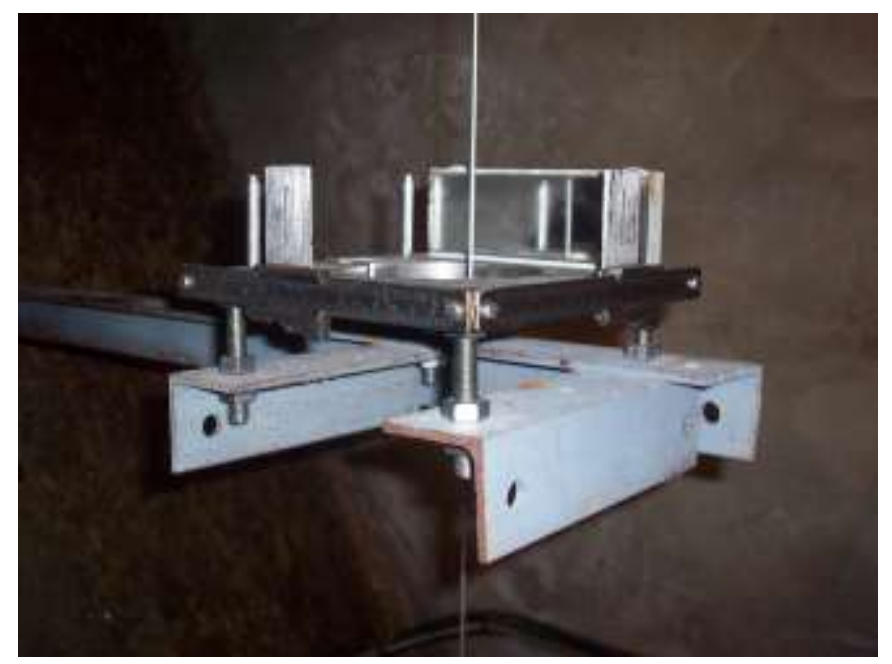

Figure 2. Reading micrometer of La Cohilla Dam pendulum-plumb.

Although pendulum-plumb is characterised by determining the location of a point in a continuous way, logs are taken each 4 or 5 days, as reading procedure is not automatized and hence, the person in charge of the dam must get there and proceed to the location of pendulum-plumb micrometer, which is not always possible due to adverse meteorological conditions at the place, specially during winter.

It is worth noting that pendulum-plumb determines any kind of movement that happens in the middle of dam crown, although due to dam geometry (circular base) this displacement is characterised by being mainly radial. This movement and its relation with temperature is exclusively analysed. This to the detriment of tangential movement, which, although it could seem to reflect temperature action (dilatation) better, on the one hand is aborved by structure joints and on the other hand, the dam is not provided with a device for its determination. The following figure shows the pendulum-plumb reference system and the characterization of both tangential and radial movements.

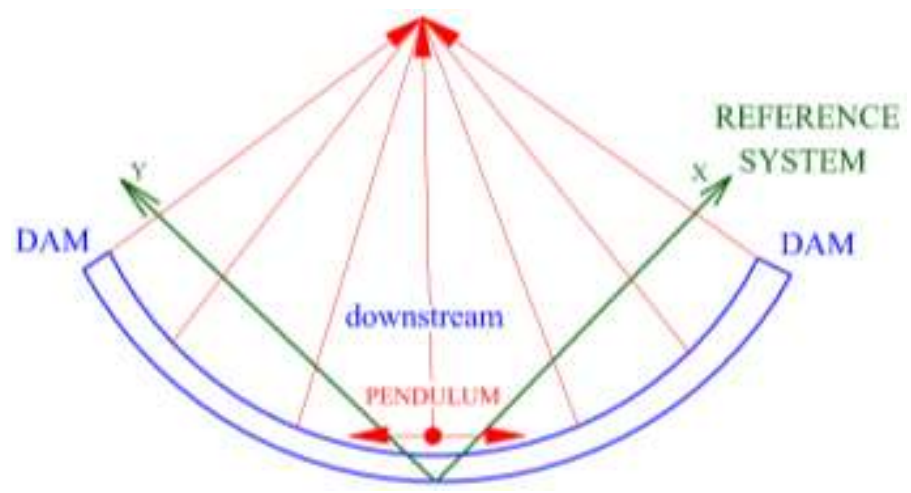

Figure 3. La Cohilla Dam pendulum-plumb reference system.

The observation of temperature is done by means of a metereological station installed on the crown of the dam, being that lecture subsequently taken to the pendulum-plumb lecture. The following figure shows the meteorological station used for the observations at La Cohilla Dam.

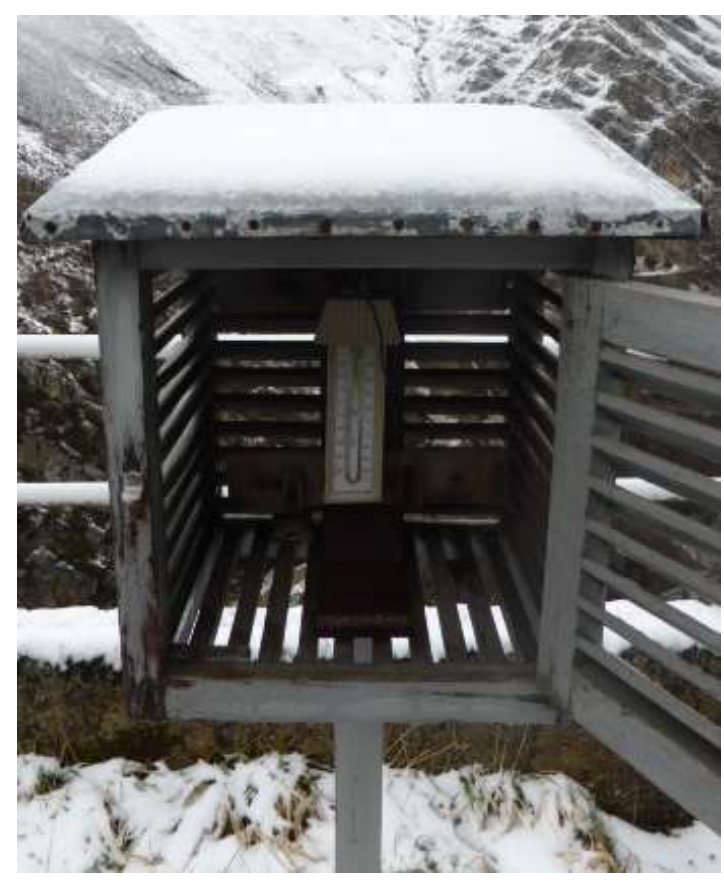

Figure 4. Meteorological Station applied at La Cohilla Dam.

Variables subjected to analysis in this research and usually observed with the devices previously described, are normally registered in a Table with the structure shown next. 
TABLE I. PENDULUM-PLUMB OBSERVABLES AND TEMPERATURE.

\begin{tabular}{|c|c|c|c|c|}
\hline Log & Date & Temp $\left({ }^{\circ} \mathbf{C}\right)$ & X_Coord $(\mathbf{m m})$ & Y_Coord $(\mathbf{m m})$ \\
\hline 4326 & 11.04 .06 & 6.8 & 7.74 & 11.38 \\
\hline 4327 & 11.04 .06 & 6.9 & 7.35 & 10.92 \\
\hline 4328 & 11.04 .06 & 6.9 & 7.38 & 11.02 \\
\hline 4329 & 11.04 .06 & 7.2 & 7.43 & 11.08 \\
\hline 4330 & 11.04 .06 & 6.6 & 7.26 & 10.87 \\
\hline 4331 & 11.04 .06 & 7.0 & 7.02 & 10.68 \\
\hline$\ldots$. & $\ldots$. & $\ldots .$. & $\ldots$. & $\ldots$. \\
\hline
\end{tabular}

Log represents the observation order, date is specified in day.month.year format, temperature comprises the average temperature for the last 30 days in Celsius degrees, and $(\mathrm{X}, \mathrm{Y})$ coordinates shows the dam crown center position in the pendulum-plumb reference system.

\section{Fundamentals}

\section{A. Relation Techniques}

The main purpose of the relation techniques is the determination of a possible relation that can exist between the variation of a certain variable with those of one or several more, being also known as correlation. On a first step, the existence or absence of relation between variables is evaluated (if it is statistically significant). After that, the possibilities to qualify it on the basis of different relation types (direct relation, inverse relation, etc.). And finally, it is determined whether this relation can be quantified by means of a standardization procedure which allows defining limit values within relation is operative.

It is worth noting that since research held in this research is focused in quantitative variables, once the relation between variables is established, it is possible to mathematical model that relation by means of Regression procedures.

\section{B. Correlation}

The most used correlation for quantitative variables with normal distribution is Pearson correlation. If variables do not show a normal distribution, Spearman or Kendall correlation are usually applied. Both correlations have become a frequent tool in software suites implemented for the development of statistical calculations, but it is important to check whether the variables show a normal distribution on a first step and hence, the correlation type to apply.

There are three elements to consider when analysing a correlation:

- Sign: Correlation expresses the grade of relation between two variables and it is quantified by a value which is called "Correlation Coefficient", whose value ranges between -1 and +1 , existing both positive and negative correlations. A positive correlation means a direct relation between variables and on the contrary, a negative correlation implies an indirect relation.
- Magnitude: The second element to consider in a correlation is magnitude, which is determined by the absolute value of Correlation Coefficient. The closer it is to the interval limits $(-1,+1)$, the bigger the correlation between variables is.

- Significance: The statement of a correlation as statistically "significant" shows the result as a not very likely consequence of randomness in a certain sampling, while a "non-significant" correlation doubts of the sample representativeness. Statistical significance is measured by means of a p-value, which ranges between 0 and 1, with two well differentiated zones within this interval, from 0 to 0.05 and from 0.05 to 1 . A correlation is significant if its p-value is lower than 0.05. If it is higher, it is considered as nonsignificant and its correlation coefficient must be considered zero.

\section{Regression}

When a significant relation is detected among two or more variables, modeling that relation by means of a mathematical equation that allows foreseeing for the dependent variable with respect to independent variables is usual. Regression consists in the generation of the mathematical expression that models the relation among two or more variables, which is not exact.

A first classification is usually established in order to characterize the different Regression types: Single-variant or Multi-variant Regression, being defined by the existence of one or more dependent variables. On a second step, Linear and Non-linear Regression are usually distinguished. The first is modeled by means of a linear function, such as a straight line, plane, hyperplane, depending on the number of variables, and the latter requires expressions which could not be linear, such as exponential or logarithmical expressions, etc. On a third step, they are usually classified considering the number of independent variables. If they have a single independent variable, they are called Simple Regressions, and if there are two or more, they are known as Multiple Regressions.

\section{Methods}

In order to assure a sufficient significance of the data used for this research, those obtained during 14 years have been processed (from 1st January 2000 to 31st December 2013), which implies a sample composed of 1242 observations and can be considered statistically consistent.

So as to work with displacements instead of coordinates and be able to develop a mathematical fit, on a first step coordinates are turned into difference of coordinates with respect to a certain position. To ease the interpretation of this displacement, the rearmost position of the dam is adopted as Po location, which is evidently fixed by the position with the lowest hydrostatic thrust. Being field observables checked, it was noted that $\log 4903$, which was taken in 14th September 2012 provided the dam rearmost position of the whole dataset [1.27/4.50], due to a malfunctioning at the bottom drainage that left the water reservoir level at $9.02 \mathrm{~m}$. 
Aplying the following expression:

$$
\text { Displ. }=\sqrt{(X-1.27)^{2}+(Y-4.50)^{2}}
$$

The displacement with respect to that initial position is obtained, which along with the average temperature measured during the previous 30 days, comprise the data that will be aimed to correlate later. In this sense, it is worth noting that the use of the average temperature for the previous 30 days is something discussable, but it tries to palliate the huge variability of temperatures that can happen in so little intervals of time, which are impossible to be assumed by the structure, being thus softened the effects associated to the terminal gradient.

TABLE II. TRANSFORMATION TO DISPLACEMENTS AND TEMPERATURES.

\begin{tabular}{|c|c|c|c|}
\hline Log & Date & Temp $\left({ }^{\circ} \mathbf{C}\right)$ & Displacement $(\mathbf{m m})$ \\
\hline 4326 & 11.04 .06 & 6.8 & 9.4 \\
\hline 4327 & 11.04 .06 & 6.9 & 8.8 \\
\hline 4328 & 11.04 .06 & 6.9 & 8.9 \\
\hline 4329 & 11.04 .06 & 7.2 & 9.0 \\
\hline 4330 & 11.04 .06 & 6.6 & 8.7 \\
\hline 4331 & 11.04 .06 & 7.0 & 8.4 \\
\hline$\ldots$. & $\ldots$. & $\ldots$. & $\ldots$. \\
\hline
\end{tabular}

\section{v. Results.}

On a first step, the normality of the independent variable sample is checked by means of Anderson-Darling Test, obtaning the following results:

TABLE III. NORMALITY TEST RESULTS.

\begin{tabular}{|c|c|}
\hline \multicolumn{2}{|c|}{ Anderson-Darling Normality Test Results } \\
\hline $\mathrm{A}^{2}$ & 16.72 \\
\hline P-value & $<0.005$ \\
\hline Average & 7.4347 \\
\hline Standard Deviation & 3.6957 \\
\hline Variance & 13.6583 \\
\hline Asimetry & -0.11560 \\
\hline Curtosis & -1.14724 \\
\hline $\mathrm{N}$ & 1242 \\
\hline 95\% Confidence Interval for the Average & $7.2290-7.6404$ \\
\hline 95\% Confidence Interval for the Median & $7.2222-8.1150$ \\
\hline 95\% Confidence Interval for Standard Deviation & $3.5559-3.8471$ \\
\hline
\end{tabular}

The results of Anderson-Darling test show that the data distribution of the independent variable (temperature) is not Normal, which can be also seen in Figure 5.

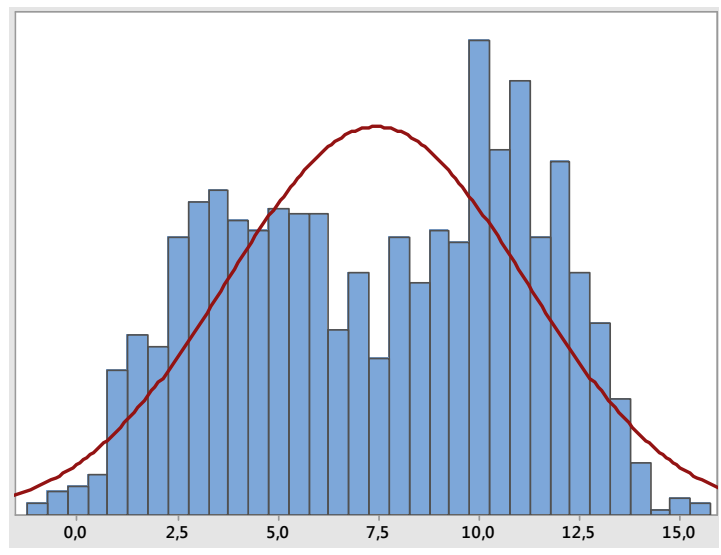

Figure 5. Independent variable (temperature) data distribution.

Once it has been determined the non-normality of the data sample, and in order to analyze the possible correlation between temperature and displacement, a diagram of dispersion is generated so as to orientate the authors about the kind of relation existing between the two variables.

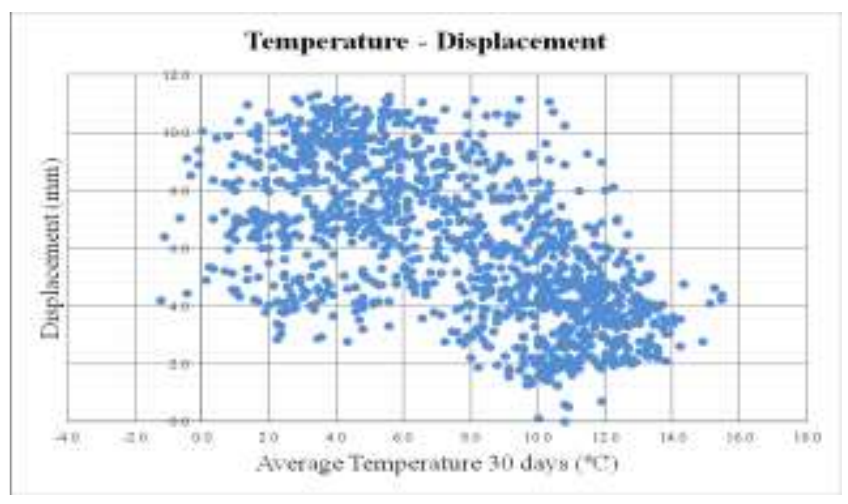

Figure 6. Temperature-displacement dispersion graphic for the data set.

The analysis of Regression is held by the study of dispersion diagram, so as to evaluate the potential correlation between variables, being conscious that a simple visual approach to this diagram shows an important dispersion of the data. So as to undergo the regression analysis, and taking into account the non-normal distribution of the data, the Spearman Correlation Coefficient is determined by means of the following expression:

$$
R s=1-\frac{6 \sum_{1}^{n} d^{2}}{n \cdot\left(n^{2}-1\right)}
$$

Where:

$$
\begin{aligned}
& \mathrm{d}=\text { Difference of ranks. } \\
& \mathrm{n}=\text { Number of observations. }
\end{aligned}
$$

The result of Spearman Correlation Coefficient is equal to -0.558 and the p-value tends to zero, which indicates that the correlation between temperature and the radial deformation of 
the dam is an inverse one, and with a low enough correlation value to discard a perfect correlation between both variables, though it can be considered as moderated and significant. Despite the above, a simple linear regression has been obtained in order to get an approach to the expression that can be applied to relate both variables:

$$
\text { displac }=9.0737-0.3935 \cdot \text { temp }
$$

The substitution of temperature expressed in Celsius degrees in this mathematical equation provides a guiding value for the displacement in millimeters.

\section{Discussion}

The first discussion line arisen from this work focuses in the deformation typology considered for the development of this research, the decomposition in radial and tangential deformation implies that the most important part of the deformation produced by structure dilatation has an exclusively tangential character, which in addition justifies the result obtained. However, it is worth mentioning that this research aims to correlation temperature and radial deformation to determine whether there is a contribution from temperature to radial movement or not.

The second discussion line that emerges from this work of research is focused in the observation of temperature, which is obviously taken outside and therefore does not match the structure temperature. In this sense, the average environmental temperature measured during the previous thirty days was adopted as valid value for the structure temperature, providing a better fit of this thermal gradient with respect to the time required for the structure to modify its temperature. It is worth noting that other measures could have been applied, but literature consulted recommends thirty days.

Being conscious of the moderated Spearman Correlation Coefficient obtained, a simple linear regression has been obtained. Other non-linear fits (polynomial, logarithmic, etc.) could have been applied, but given its guiding character, it was not worth considering a deeper approach adoption. It is worth mentioning that deformation can be correlated to other variables which also show influence, such as hydrostatic thrust, although that relation was obtained, since this research main aim was the isolation of temperature influence on deformation.

\section{vII. Conclusions}

The development of this research has provided a methodology that allows relating variables which affect the potential deformation of a structure. In this case, it has been applied to a certain type of structure, but it can be used with other kind of structures or other variables, in order to establish predictive models which allow delimiting the deformations under extreme conditions.

Given the results obtained and the above mentioned, it can be concluded that in this study case an univariant linear regression between radial deformation and temperature has been held. This regression has a guiding character as variables show moderated correlation between them, but it allows checking the structure stress state and obtaining another clue about the structural safety of the dam, which is a matter to worry for its managers.

\section{Acknowledgments}

It has been possible to develop this work thanks to the data provided by the Enterprise Saltos del Nansa, which is constantly supporting research developed by this Area of Knowledge of University of Cantabria.

\section{References}

[1] Chueca Pazos, M. et al., "Redes topográficas y locales". Servicio de Publicaciones de la Universidad Politécnica de Valencia. 1994.

[2] Fan, H., "Theory of Errors and Least Squares Adjustment". Royal Institute of Technology. Stockholm. 2005.

[3] Ferrer Torio, R., et al., "Geodetic Deformation Monitoring: From Geophysical to Engineering Roles", International Association of Geodesy Symposia, Vol. 131, 2005, pp. 270-276

[4] De Luis Ruiz, J.M. "Auscultaciones geodésicas por métodos clásicos y con Láser Escáner”. Editorial Académica Española, 2012, pp. 179-184.

[5] De Luis Ruiz, J.M., Piña García, F., Pereda García, R., "Contrast between angular and distance observables in geodetic inspection of deformation”. DOI: 10.15224/ 978-1-63248-030-9-59

[6] De Luis Ruiz, J.M., Pereda García, R., Piña García, F., Pérez Álvarez, R., "Determination of an empirical model for calculating the strain of a dam in terms of hydrostatic thrust".

[7] Llopis Pérez, J., "La estadística: una orquesta hecha instrumento", Editorial Ariel, 1996.

[8] Luceño Vázquez, A., et al., "Métodos estadísticos para medir, describir y controlar la variabilidad", Editorial Universidad de Cantabria, 2005, pp.68-73.

[9] Sevilla de Lerma, M.J., "Colocación mínimos cuadrados". IV Curso de Geodesia Superior, Instituto de Astronomía y Geofísica, Madrid, 1987.

[10] Sundakov, Y.A., "Trabajos geodésicos en la construcción de grandes obras industriales y altos edificios”, Editorial Mir, 1980. 